\title{
Evaluation of cryotherapy in the management of epulis in dogs
}

\begin{abstract}
Six dogs with clinically and histologically confirmed epulis were included in this study. Five dogs had a localized smooth; non-ulcerated oral mass protruded from the margins of either lower or upper lips whereas in one animal ulcerated, diffuse and areas of necrosis located at lower jaw was seen. During physical examination mass was detected in the oral cavity originated from the gums, darkly pigmented, varied in sizes and foul smelling. All tumours were histologically benign except one. Fibromatous and acanthomatous epulis were observed. In one case distant pulmonary metastasis was confirmed radiologicaly. Nitrous oxide cryoprobe was used in benign cases (5) to excise these tumours under general anesthesia. Nanosomal docetaxel was used as chemotherapy in one metastatic case. Complete healing without any postoperative complications was observed in cryosurgery. No recurrence was observed after six months of cryoablation. Chemotherapy in metastatic epulis cases was found unsatisfactory. It may be concluded that cryosurgery can be used for treatment of benign epulis in canines.
\end{abstract}

Keywords: Dog, epulis, cryosurgery, chemotherapy
Volume 3 Issue 4 - 2018

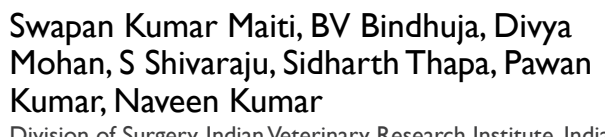

Division of Surgery, Indian Veterinary Research Institute, India

Correspondence: Swapan Kumar Maiti, Principal Scientist, Surgery Division, Indian Veterinary Research Institute, Izatnagar-243 I22, Uttar Pradesh, India, Tel +94 I2049I69, Fax +91 58I 2303284,Email swapanikri@gmail.com; malti_62@rediffmail.com

Received: September 13,2018 | Published: October 10, 2018

\section{Introduction}

Epulis are tumourous growths originating from the animal's gums and alveoli. They appear early on as small masses sprouting from the gum; hangs from a stalk like structure and during expansion they generally displace tooth structures. They are more commonly met with in dogs. These are usually benign tumours and they do not spread to other organs of the body; however, have tendency to recur. The tumour is firm and hard in consistency; may be grey, pink or bright red and is located at the gingival margin, but do not arise from the teeth. The animal may frequently rub the mouth with paws. Impaired appetite, difficulty in mastication, bad odor from the mouth is the characteristic symptoms. ${ }^{1}$ There are three different types of epulis: fibromatous, ossifying and acanthomatous observed in canines. ${ }^{2}$

Cryosurgery is defined as a method where locally extreme cold application is used to destroy abnormal or diseased tissue without any damage to normal adjacent healthy tissue. Tissue temperature should reach $-20^{\circ} \mathrm{C}$ or below. ${ }^{3}$ Attempts are taken to kill all tissues in the target with minimal damage to surrounding tissues. The advantages of cryosurgery include virtually painless application, lack of hemorrhage, minimal scarring and no need for stitches. ${ }^{4}$ Cryosurgery has been used in treatment of skin tumours, ${ }^{5}$ bone tumours, ${ }^{6}$ prostate and liver tumours $^{7}$ and maxillo-facial sarcoids and vulvar leiomyomas. ${ }^{4}$ The agents used for cryotherapy include solid or liquid carbon dioxide, liquid or gaseous nitrous oxide and liquid nitrogen.

So far, there is paucity of literature regarding use of cryosurgery in veterinary patients, therefore, the present study was undertaken to evaluate the efficacy of cryotherapy in the treatment of epulis in dogs.

\section{Materials and methods}

This study was carried out in six dogs of different breeds and ages, with variable sizes of epulis, which presented at the Institute's Referral Veterinary Polyclinics, India. Details of these cases are given in Table 1. Out of 6 animals, in two males and females, growth was seen at upper jaw, while in other two female's dog, growth was seen at lower jaw (Figures $1 \mathrm{~A}-1 \mathrm{~F})$. All animals were unable to take food or drink properly and were having foul smelling odour from mouth.

Table I Animal case history

\begin{tabular}{|c|c|c|c|c|c|c|c|}
\hline $\begin{array}{l}\text { SI } \\
\text { No }\end{array}$ & Animal & Breed & $\begin{array}{l}\text { Age } \\
\text { (years) }\end{array}$ & Sex & Tumour location (tumour size) & $\begin{array}{l}\text { Histopathological } \\
\text { Diagnosis }\end{array}$ & Metasta-sis \\
\hline I & Dog & Spitz & 6.5 & Female & $\begin{array}{l}\text { Right upper jaw-anterior to canine } \\
\text { teeth }(8 \mathrm{~cm} \text { in diameter })\end{array}$ & $\begin{array}{l}\text { Fibromatous } \\
\text { Epulis }\end{array}$ & Absent \\
\hline 2 & Dog & Spitz & 8 & Female & $\begin{array}{l}\text { Right upper jaw- posterior to } \\
\text { canine teeth ( } 12 \mathrm{~cm} \text { in diameter) }\end{array}$ & $\begin{array}{l}\text { Fibromatous } \\
\text { Epulis }\end{array}$ & Absent \\
\hline 3 & Dog & Spitz & 7 & Male & $\begin{array}{l}\text { Right upper jaw -anterior to canine } \\
\text { teeth }(7 \mathrm{~cm} \text { in diameter })\end{array}$ & $\begin{array}{l}\text { Fibromatous } \\
\text { Epulis }\end{array}$ & Absent \\
\hline 4 & Dog & Spitz & 8.5 & Male & $\begin{array}{l}\text { Left upper jaw -posterior to canine } \\
\text { teeth }(5 \mathrm{~cm} \text { in diameter })\end{array}$ & $\begin{array}{l}\text { Fibromatous } \\
\text { Epulis }\end{array}$ & Absent \\
\hline 5 & Dog & Spitz & 6 & Female & $\begin{array}{l}\text { Lower jaw-involving lower incisor } \\
(9 \mathrm{~cm} \text { in diameter })\end{array}$ & $\begin{array}{l}\text { Fibromatous } \\
\text { Epulis }\end{array}$ & Absent \\
\hline 6 & Dog & Labrador & 10 & Female & $\begin{array}{l}\text { Lower jaw- involving canine and } \\
\text { incisor ( } 12 \mathrm{~cm} \text { in diameter) }\end{array}$ & $\begin{array}{l}\text { Acanthomatous } \\
\text { Epulis }\end{array}$ & Present \\
\hline
\end{tabular}




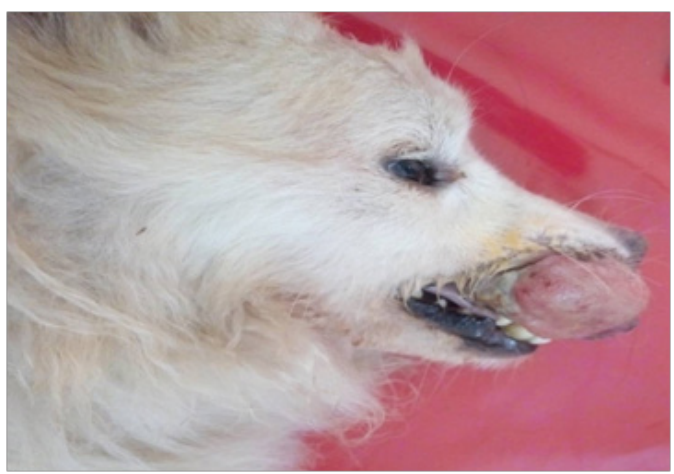

Figure I(A) Epulis at right upper jaw.

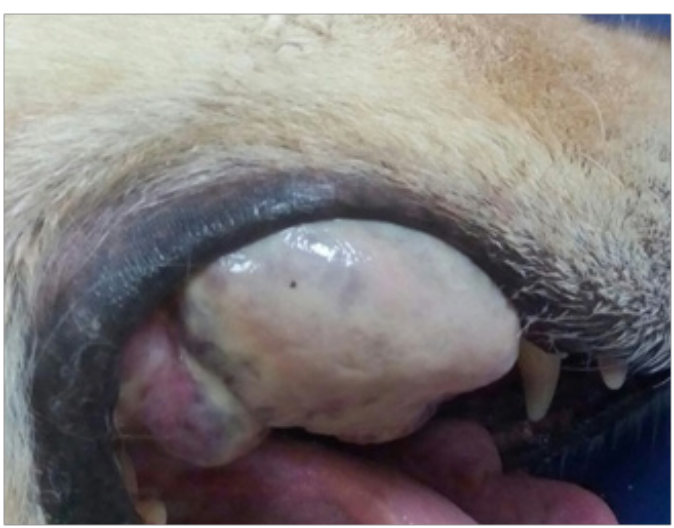

Figure I(B) Epulis at right upper jaw.

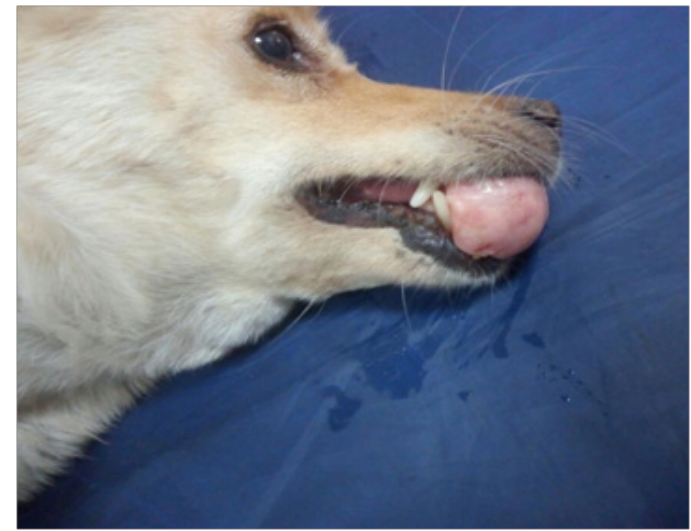

Figure I(C) Epulis at right upper jaw.

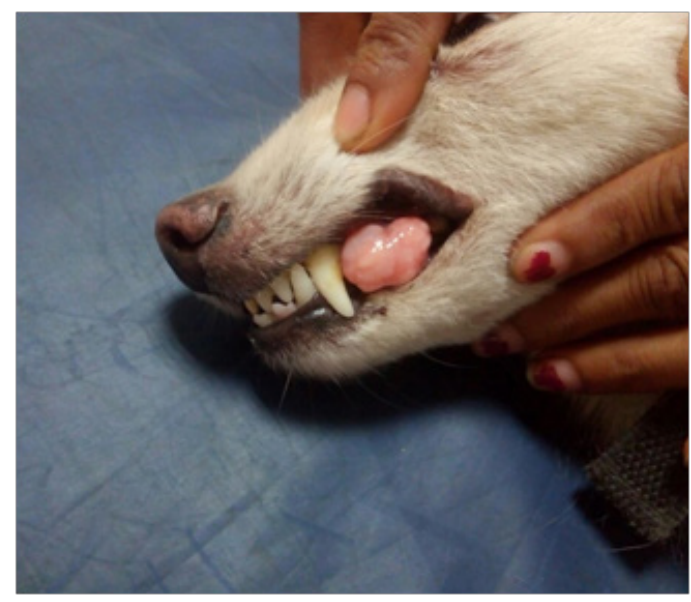

Figure I(D) Epulis at right upper jaw.

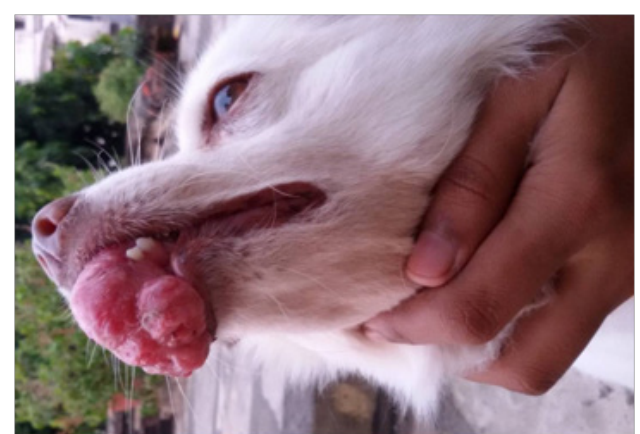

Figure I(E) Epulis at lower jaw.

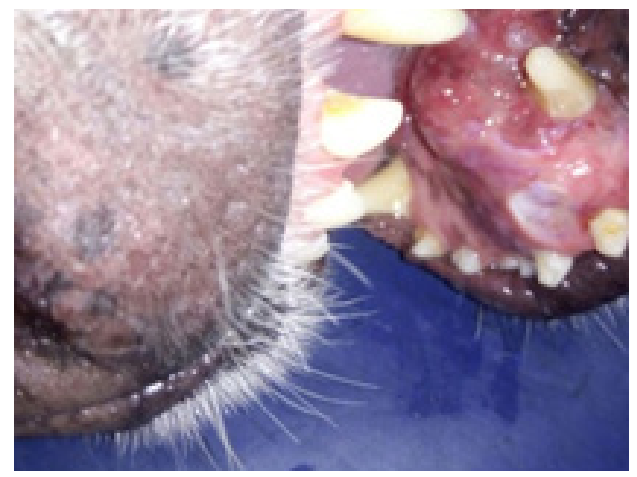

Figure I(F) Epulis at lower jaw

Thoracic radiographs were taken in all these patients to detect the possible presence of lung metastasis. Preoperatively, tumour biopsy samples were collected before any therapy under xylazine-ketamine anesthesia, fixed immediately in 10\% neutral buffered formalin and processed routinely by paraffin embedding technique. Sections of 4-5 microns thickness were cut and stained by haematoxylin and eosin (H\&E) for histopathological examination.

In five animals cryosurgery was performed after confirming the histological nature (benign) of the tumourous growth. The owner's consent was also taken into consideration before surgical therapy. The animals were fasted for $24 \mathrm{~h}$ and deprived of water for $6 \mathrm{~h}$ before anaesthesia. Each animal was premedicated with Meloxicam (a) $0.1 \mathrm{mg} / \mathrm{Kg}$ body weight intramuscularly and Ceftriaxone sodium (a) $10 \mathrm{mg} / \mathrm{kg}$ body weight intramuscularly, approximately $1 \mathrm{~h}$ before surgery. The surgical site was shaved, cleaned and scrubbed with chlorhexidine solution, wiped with $70 \%$ alcohol and pained with povidone iodine.

All animals were premedicated with Atropine sulphate @ 0.04mg/ kg body weight subcutaneously. After 10 minutes, anaesthesia was followed with Xylazine hydrochloride @ 1mg/kg body weight intramuscularly followed by induction with Ketamine hydrochloride @ $5 \mathrm{mg} / \mathrm{kg}$ body weight after 10 minutes. If required, anesthesia stage was prolonged by intravenous administration of combination of Ketamine hydrochloride@5g/kg body weight and Diazepam @ 0.2/ $\mathrm{kg}$ body weight. The animals were kept in lateral recumbency with the affected part on the upper side. The surgical site was prepared for aseptic surgery and resection of the mass was done using nitrous oxide cryoprobe. Tumour masses were excised at the base level surrounding gingival mucosa. A cryosurgery system with continuous circulation contact tips was used (Figures 2A-2F). Two freezing cycles were applied. After the resection of the mass, the area, if required, coagulative sponge was applied for few minutes to stop further bleeding. The cryonecrotic scar, if any, was allowed to slough naturally. 


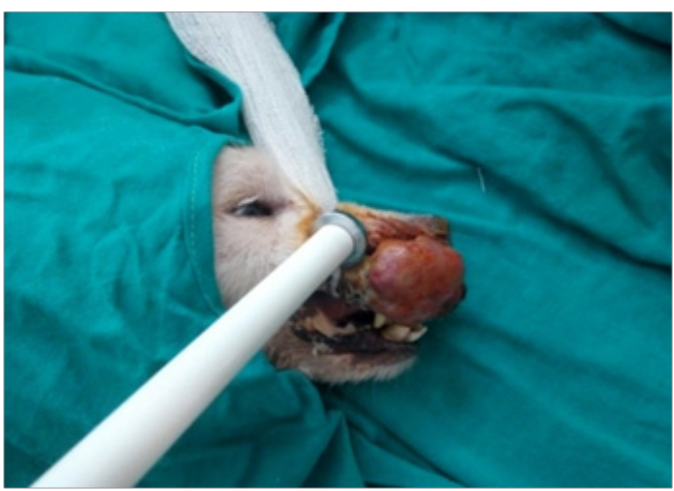

Figure 2(A) Application of nitrous oxide cryoprobe for cryoablation of the upper jaw tumour mass

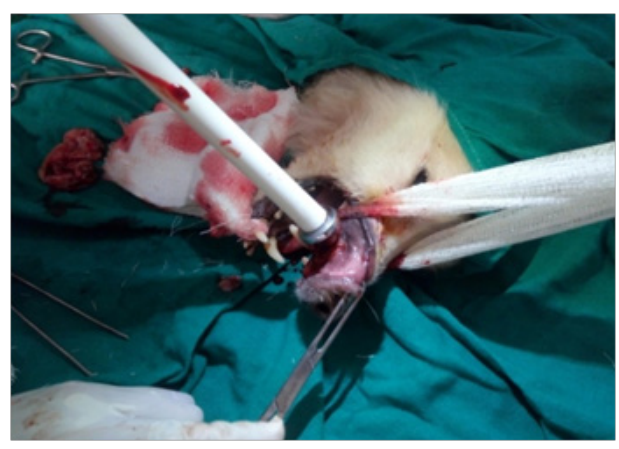

B

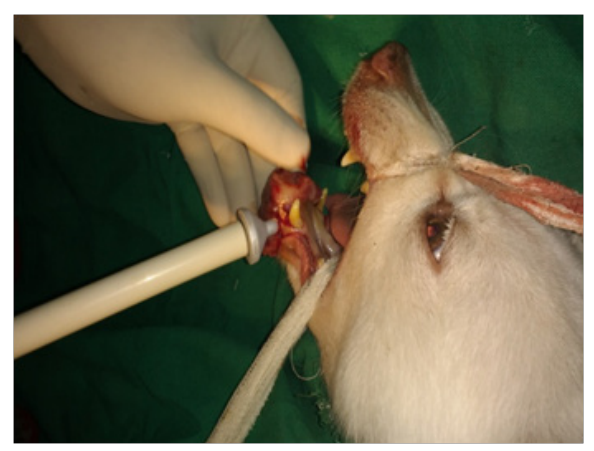

C
All the animals were hospitalized for 5days. Postoperative analgesia was provided by Meloxicam @ $0.1 \mathrm{mg} / \mathrm{Kg}$ body weight intramuscularly and Ceftriaxone sodium @10mg/kg body weight intramuscularly, once daily for five days. Surgical site was dressed twice daily with diluted Povidone iodine solution. All the cases were under surveillance for six months post-surgery for any recurrence, if any, by regular telephone conversions with the pet owners.

In one clinical case, gingival mass appeared as an irregular surface that was ulcerated with areas of necrosis in lower jaw. As distant metastatic lesions were confirmed radiologically; chemotherapy with nanosomal Docetaxel was given intravenously@30mg per kg body weight at 21days interval, with the consent of animal owner.

Necessary permission was obtained from the Institute's Animal Ethics Committee (IAEC) to conduct this research on clinical cases.

Figure 2(B-D) Application of nitrous oxide cryoprobe for cryosurgery of the lower jaw tumour mass

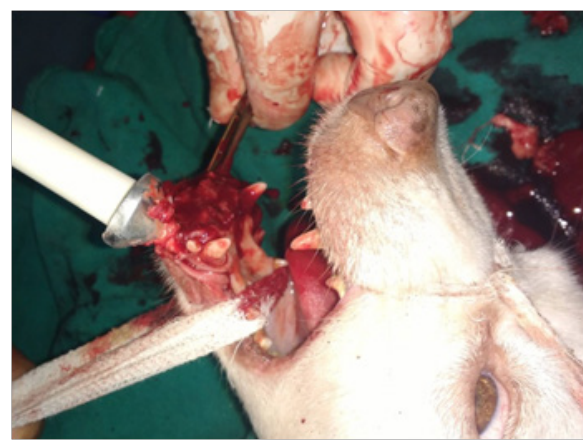

D

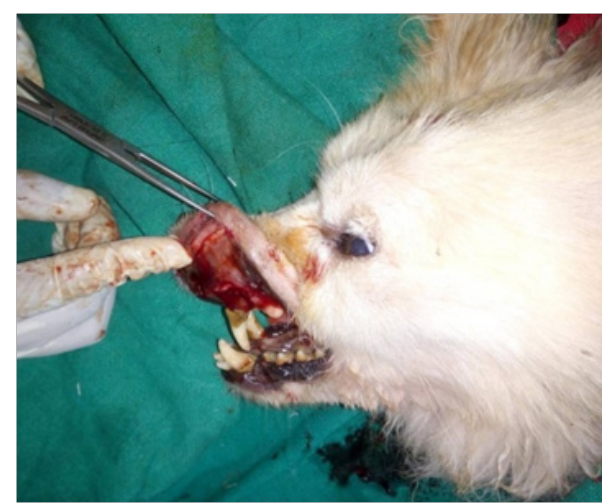

Figure 2(E) Complete cryoablation of upper jaw tumour mass

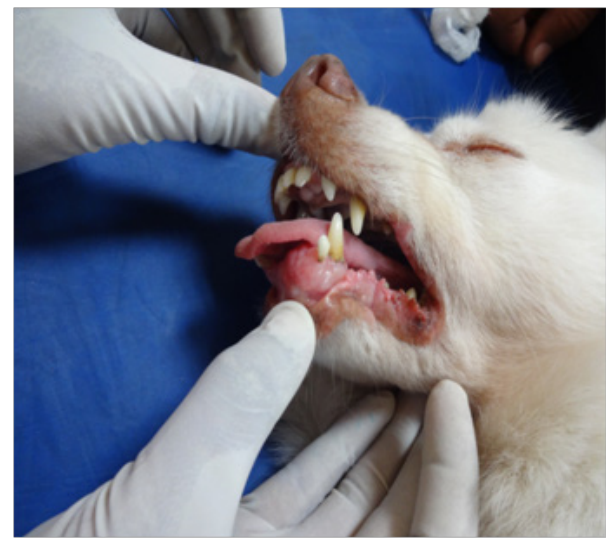

Figure 2(F) Complete healing of lower epulis on I2th postoperative days.

\section{Results}

History revealed that these tumours developed vigorously within a very short period of time. In five animals (all were Spitz), the tumour masses were generally smooth to slightly nodular surface, non-ulcerated, pinkish to red in colour and originating from the gum (Figures 1A-1E), whereas in one animal (Labrador) tumour mass was diffused, ulcerated, areas of necrosis and originating from periodontal ligament in lower jaw (Figure 1F). The size of each tumour mass was measured by Vernier caliper and diameter was ranged in between 5-12 $\mathrm{cm}$. Radiological examination revealed distant pulmonary metastases in one animal (Figure 3A). In this case, extensive destruction of bone with displacement of adjacent teeth was also observed (Figure 3B). All the cases that underwent cryosurgery had an uneventful recovery. The animals appeared quite alert and responsive throughout the postoperative period. Postoperative complications, such as infection, wound dehiscence were not observed in any case. Complete wound healing was observed on the $12-15^{\text {th }}$ day post-cryosurgery. No sign of any recurrence was observed up to six months post cryoablation.

Histologically, all but one tumour were diagnosed as fibromatous epulis. The microscopic features of the fibromatous epulis consisted predominantly of cellular fibroblastic connective tissue which often interwoven with a loose connective tissue and superficial layer of the squamous epithelium having irregular projections. The capillaries were located within the looser connective tissue and there was some focuses of collagenous matrix were also present (Figure 4A). The histopathological examination in one case of lower jaw epulis revealed acanthomatous epulis, which were characterized by consist of islands and cords of squamous epithelium that have invaded irregularly in adjunct of connective tissue. Basal columnar cells were arranged 
with their long axes perpendicular to the basement membrane, and some exhibited vacuolated cytoplasm. These basal cells typically surrounded by sheets of squamous epithelium having intercellular bridges (Figure 4B).

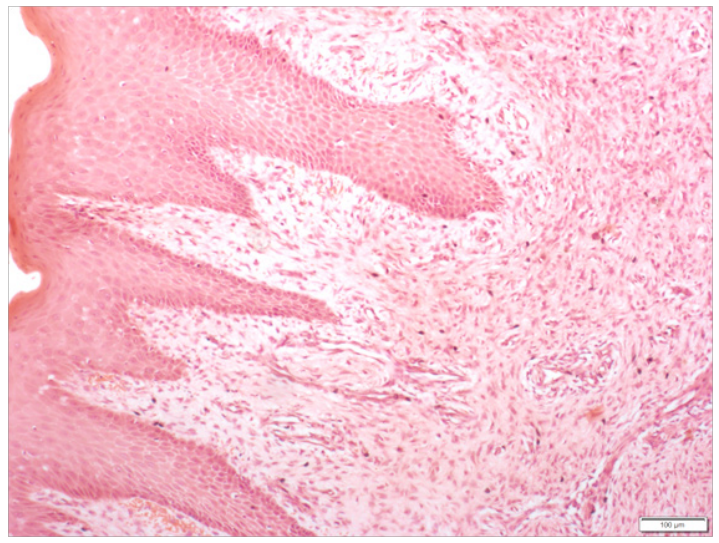

Figure 3(A) Photomicrograph of fibromatous epulis (H\&E x 200).

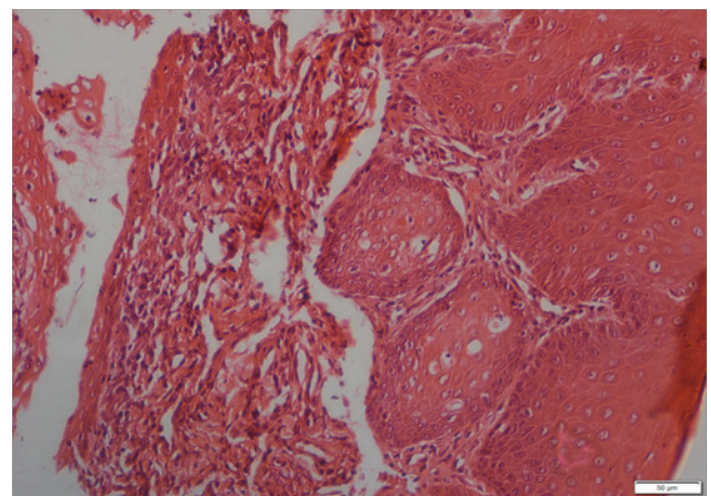

Figure 3(B) Photomicrograph of acanthomatous epulis (H\&E x 200).

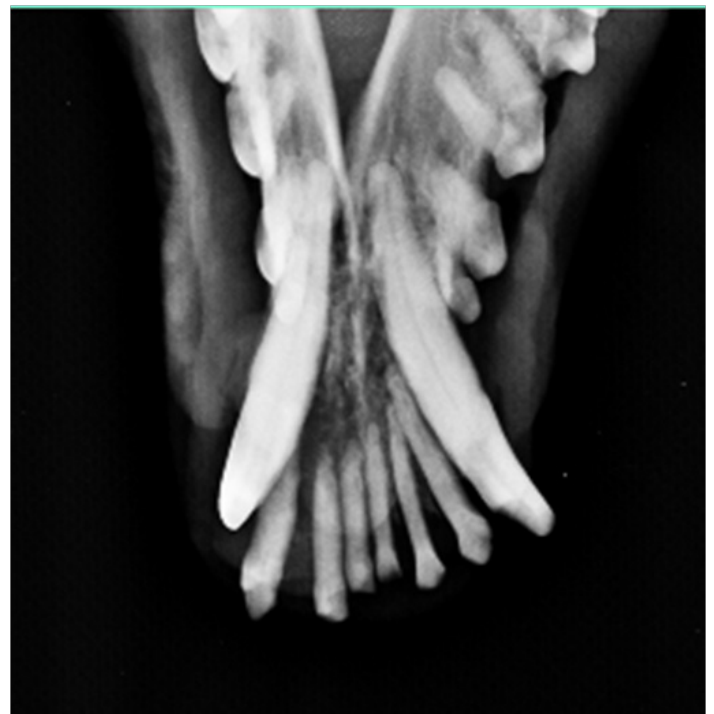

Figure 4(A) Radiograph of acanthomatous epulis depicting bone destruction.

In single case of acanthomatous epulis, chemotherapeutic agentnanosomal Paclitaxel was given as distant pulmonary metastasis was also recorded in this case. Though, there was some regression of tumour mass recorded after first dose of chemotherapy, however, even after third dose of chemotherapy this regression was unsatisfactory.
Tumour mass became more aggressive and ulcerated with profound foul smelling along with continuous bloody discharge. Animal's condition deteriorated drastically. As per request of the animal owner, euthanasia was performed, as owner was not interested to further chemotherapy or any surgery (partial mandibulectomy).

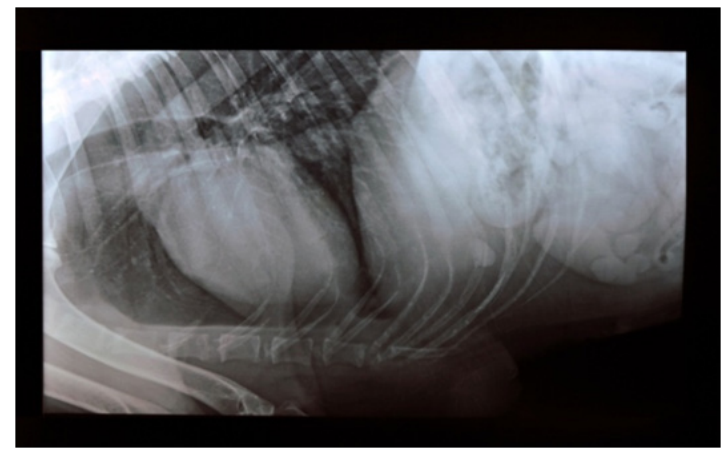

Figure 4(B) Lateral thoracic radiograph showing metastasis in an epulis case.

\section{Discussion}

Canine epulis are the fourth most common oral tumour in dogs and more incidences in brachyecephalic breeds, however, in this study it was mostly found in Spitz. Among the three types of epulis, fibromatous epulis is more common in canines. The etiology of canine epulides is not known so far. In canine, fibromatous epulis is characterized histopathologically by a mass of cellular, fibroblastic connective tissue which is separated from the surface epithelium by a zone of normal fibrous connective tissue. ${ }^{8,9}$ It generally does not invaded into the bone or mandible and occurred in canines over 5years of age. Similar clinical and histopathological lesions of fibromatous epulis also observed in this study in five clinical cases involving either upper or lower jaw and all cases were aged above 5years.

Incidence of ossifying epulis in dogs is very rare and it's originated from fibrous and bone tissues and more chances of malignant. Surgery is the choice of treatment; however, complete removal is very difficult. Cryosurgery is generally advisable in these cases. In this study, we do not record any case of ossifying epulis.

In canine, acanthomatous epulis are common and it's characterized by its aggressiveness and invasiveness to the bone. It generally destroys the bony structure and can occur in any part of the jaws, ${ }^{10}$ however, more incidences in the anterior part of the mandible. ${ }^{8,11}$ Histopathologically, the basal cells are palisades, columnar and exhibited cytoplasmic vacuolation. Similar clinical and histopathological lesions were recorded in one case of acanthomatous epulis in this study.

In this study, fibromatous epulides were resected by cryoablation. The anesthesia for cryoablation was found optimum. After achieving surgical anesthesia, animals were properly restrained and surgical site was prepared for aseptic surgery. Surrounding healthy tissues was shielded with gauze pads smeared with petroleum jelly to avoid spreading of cryogen to healthy tissues. Tumour mass was exercised using nitrous oxide $\left(\mathrm{N}_{2} \mathrm{O}\right)$ cryoprobe. Two freezing cycles were applied in each surgery for complete removal of tumour masses. Haemorrhage was negligible and the whole procedure was very easy, rapid and safe. Complete healing was observed in five cases treated by cryosurgery by the end of two weeks without any postoperative complications. No recurrence was observed after 6 months of surgery. Surgical removal of the tumour is commonly practiced, but recurrence is a major problem encountered. Chemotherapy, radiation therapy or 
diathermy alone or in combination with surgical excision has been tried but, cryotherapy was found superior due to its analgesic and haemostatic effects, apart from being simple, quick and economical., ${ }^{4}$

Cryosurgery is a safe and easy procedure and can be used for removal of external tumours in animals in cases where the tumour mass is large and diffused. The advantages of cryotherapy includes the absence of pain, no risk of dissemination of tumour cells, low risk of infection, minimal hemorrhage, less possibility of repeating the intervention, normal physiological functions and no scar formation. The procedure is easy and rapid to perform with low costs. Disadvantages include no direct estimation of the effect, the lesion is unpleasant to see and smell, postoperative edema may occur and the area remains depigmented. ${ }^{13}$ However, in this study, no postoperative complications were recorded and complete healing was observed in all treated cases.

For the treatment of acanthomatous epulis, radiation therapy has been tried with varied success rate by different workers. ${ }^{10,14}$ In this study, we have tried to treat single case of acanthomatous epulis with chemotherapeutic agent-nanosomal Paclitaxel, which was found very safe and without any side effects and showed regression the tumour mass initially, however, complete regression was not achieved.

\section{Conclusion}

Cryosurgery can be used for treatment of benign epulis in canines.

\section{Acknowledgements}

None.

\section{Conflict of interest}

Author declares there is no conflict of interest towards the manuscript.

\section{References}

1. Venugopalan A. Essential of Veterinary Surgery. 8th ed. USA: Oxford \& IBH Publishing Co Pvt. Ltd; 2002. 307 p.
2. Crosby JT. What is epulis in dogs, and how is it treated.

3. Cahan WG. Cryosurgery of malignant and benign tumors. J Saint Barnabar Med Centre. 1967;4:285-294.

4. Maiti SK, Kumar N, Mathew D, et al. Cryosurgical treatment of equine maxillo-facial sarcoids and vulvar leiomyomas. Proc Natal Acad Sci, India, Section B: Biol Sci. 2015;85(1):107-112.

5. Zouboulis CC. Principles of cutaneous cryosurgery: an update. Dermatology. 1999;98(2):111-117.

6. Costa FWG, de Castro Brito G A, Pessoa RMA, et al. Effect of different cryosurgical protocols using liquid nitrogen on bone tissue: a histomorphological analyze. J Clin Exp Dent. 2011;3(2):91-96.

7. Brown NJ, Bayjoo P, Reed MW. Effect of cryosurgery on liver blood flow. Br J Cancer. 1993;68(1):10-12.

8. Gardner DG, Baker DC. The relationship of canine acanthomatous epulis to ameloblastoma. J Comp Pathol. 1993;108(1):47-55.

9. Gardner DG. Epulides in the dog: a review. J Oral Pathol Med. 1996;25(1):32-37.

10. Thrall DE. Orthovoltage radiotherapy of acanthomatous epulis in 39 dogs. J Am Vet Med Assoc. 1984;184(7):826-829.

11. Langham RF, Mostosky UV, Schirmer RG. X-ray therapy of selected odontogenic neoplasms in the dog. J Am Vet Med Assoc. 1977; 170(8):820-822.

12. Baxter JS. The technique of veterinary cryosurgery and the machinery of veterinary cryosurgery. J Small Anim Pract. 1978;19:27-41.

13. Cooper SM, Dawber RPR. The history of cryosurgery. $J$ R Soc Med. 2001;94(4):196-201.

14. White RAS, Jeffries AR, Gorman NT. Sarcoma development following irradiation of acanthomatous epulis in two dogs. Vet Rec. 1986;118(24):668. 